\title{
Monitoring Dynamics of DNA Methylation at Single-Cell Resolution during Development and Disease
}

\author{
Yonatan STElZER ${ }^{1}$ AND RUdolf JaEnisch ${ }^{1,2}$ \\ ${ }^{1}$ Whitehead Institute for Biomedical Research, Cambridge, Massachusetts 02142 \\ ${ }^{2}$ Department of Biology, Massachusetts Institute of Technology, Cambridge, Massachusetts 02142 \\ Correspondence: jaenisch@wi.mit.edu
}

\begin{abstract}
DNA methylation is a broadly studied epigenetic modification that is essential for normal mammalian development. Over the years, numerous methodologies were developed trying to cope with the intrinsic challenge of reading the "second dimension" epigenetic code. The recent rapid expansion of sequencing technologies has made it possible to fully chart the methylation landscape of different cell types at single-base resolution. Surprisingly, accumulating data suggest that, in addition to the massive epigenome remodeling during early development, cell type and tissue specification is associated with high levels of DNA methylation dynamics at distal regulatory elements. However, current methods provide only a static "snapshot" of DNA methylation, thus precluding the study of real-time methylation dynamics during cell fate changes. Here we review the principles of a new approach that enables monitoring loci-specific DNA methylation dynamics at single-cell resolution. We also discuss potential applications and promises for implementing this methodology to study DNA methylation changes during development and disease.
\end{abstract}

In vertebrates, DNA methylation consists of the addition of methyl groups to the fifth carbon atom of cytosine nucleotides, mostly in the symmetrical form of CpG dinucleotides (Smith and Meissner 2013). As one of the first epigenetic alterations to be identified (Holliday and Pugh 1975; Riggs 1975), DNA methylation represents perhaps the most studied and mechanistically best-understood modification. The methyl marks are established by de novo DNA methyltransferases (Dnmt3a and Dnmt3b) and carried through to daughter cells via specific maintenance methylase (Dnmt1) in a tightly regulated manner, thus providing a robust heritable mechanism (Morgan et al. 2005). Once established, DNA methylation is a rather permanent and stable modification and in agreement with that the bulk genomic methylation patterns are mostly static between cell types and tissues. However, in marked contrast to the overall stability of methylation in adult tissues, global methylation patterns are highly dynamic during two stages that are cornerstones of developmental biology. (i) After fertilization, the genome is broadly demethylated followed by global de novo methylation in the postimplantation embryo. Subsequently, during later development and cellular differentiation, local demethylation correlates with the activation of tissue-specific genes. (ii) During primordial germ cell specification, global as well as parent-specific methylation marks are erased to be reestablished in a sex-specific manner during gametogenesis (Heard and Martienssen 2014; Lee et al. 2014).

DNA methylation is essential for normal mammalian development as indicated by embryonic and postnatal lethality upon Dnmt1 and Dnmt3 deletion in mice (Li et al. 1992; Okano et al. 1999). These mutant mice provided a genetic tool to study the effect of DNA me- thylation on imprinting (Li et al. 1993), X inactivation (Panning and Jaenisch 1996), and cancer (Laird et al. 1995). In humans, misregulation of DNA methylation is associated with numerous diseases including imprinting disorders, neurodegenerative syndromes, and repeat sequence instability (Robertson 2005). Furthermore, multiple lines of evidence have indicated that changes in methylation are correlated with different stages of cancer progression and metastasis in various types of tumor (Baylin and Jones 2011). The potential cellular consequences of global DNA methylation changes are diverse, ranging from chromosomal instability and genetic mutation to reactivation of cellular oncogenes and down-regulation of tumor suppressors (Feinberg and Vogelstein 1983; Chen et al. 1998; Eden et al. 2003; Gaudet et al. 2003).

In recent years, development and improvement of nextgeneration sequencing methodologies (Lander 2011) enabled genome-wide base-resolution methylomes of multiple tissues and cell types across different species (Hon et al. 2013; Smith et al. 2014; Roadmap Epigenomics Consortium et al. 2015; Schultz et al. 2015). This unprecedented increase in available data has revolutionized the field, promising to significantly enhance our understanding of the role of DNA methylation, together with other epigenetic modifications, in maintaining and regulating cell fate (Rivera and Ren 2013; Romanoski et al. 2015). In this article, we first review the key methodologies used in the field to study DNA methylation, ranging from baseand locus-specific to genome-wide methods (Harrison and Parle-McDermott 2011). We then focus on a recent novel experimental approach that enables a real-time readout of locus-specific methylation changes at singlecell resolution (Stelzer et al. 2015). 


\section{READING THE METHYLOME: FROM SINGLE-SITE TO WHOLE- GENOME ANALYSIS}

Numerous technologies have been developed to address the inherent challenge of reading the "second-dimension" epigenetic modifications. Different approaches, ranging from nonspecific to whole-genome DNA methylation analysis with single-base resolution, are summarized in Table 1. Following the seminal papers of Holliday, Pugh, and Riggs in the mid-1970s, methods to discriminate between methylated $(5 \mathrm{mC})$ and unmethylated cytosines were developed. In the late 1970 s researchers used isoschizomers, pairs of restriction enzymes that show intrinsic sensitivity to $5 \mathrm{mC}$, reporting on the methylation state of single CpG dinucleotides (Bird and Southern 1978; Cedar et al. 1979). Subsequently, reversed-phase highperformance liquid chromatography (RP-HPLC) was used to quantitatively measure total $5 \mathrm{mC}$ levels (Kuo et al. 1980). The technology was further improved by incorporating mass spectrometry (Annan et al. 1989) and restriction endonucleases, thus facilitating discrimination between methylated and unmethylated cytosines (Bestor et al. 1984). These methods were implemented to extensively compare ballpark differences across different species (Gama-Sosa et al. 1983) and between tissues (Bestor et al. 1984; Monk et al. 1987). However, RPHPLC and mass spectrometry are limited as only relative ratios between methylated and unmethylated cytosines can be compared.

Two major breakthroughs that revolutionized the field allowed the measurement of genome-wide distribution of DNA methylation at single nucleotide resolution: (i) the discovery that $5 \mathrm{mC}$ is accessible to specific antibodies (Adouard et al. 1985), thus facilitating the generation of anti-5mC monoclonal antibodies (Oakeley et al.

Table 1. Summary of methods for analyzing CpG methylation

\begin{tabular}{ll}
\hline Method & \multicolumn{1}{c}{ Authors (year) } \\
\hline $\begin{array}{l}\text { Site-specific methylation-sensitive } \\
\text { restriction enzymes }\end{array}$ & Bird and Southern (1978) \\
Cedar et al. (1979) \\
RP-HPLC & Kuo et al. (1980) \\
Restriction endonucleases HPLC & Gama-Sosa et al. (1983) \\
& Bestor et al. (1984) \\
Mass spectrometry HPLC & Annan et al. (1989) \\
Bisulfite sequencing & Frommer et al. (1992) \\
Methylation-specific PCR & Herman et al. (1996) \\
Anti-5mC & Oakeley et al. (1997) \\
Bisulfite-based microarrays & Gitan et al. (2002) \\
Immunoprecipitation-based & Weber et al. (2005) \\
microarrays & Keshet et al. (2006) \\
Reduced representation bisulfite & Meissner et al. (2005) \\
sequencing & \\
Whole-genome bisulfite & Lister et al. (2009) \\
sequencing & Guo et al. (2013) \\
Single-cell bisulfite sequencing & Smallwood et al. (2014) \\
& Farlik et al. (2015) \\
Reporter for loci-specific & Stelzer et al. (2015) \\
methylation changes with & \\
single-cell resolution &
\end{tabular}

RP-HPLC, reversed-phase high-performance liquid chromatography; $\mathrm{PCR}$, polymerase chain reaction.
1997); (ii) recognition that treatment of DNA with sodium bisulfite (Hayatsu et al. 1970) results in differential deamination between methylated and unmethylated cytosines (Frommer et al. 1992; Clark et al. 1994), leading to the establishment of methylation-specific polymerase chain reaction (MS-PCR) methods for detection of endogenous methylation levels (Herman et al. 1996). Following the establishment of DNA microarray technology (Southern et al. 1999), both immunoprecipitation (Weber et al. 2005; Keshet et al. 2006) and bisulfite sequencing (Gitan et al. 2002; Sandoval et al. 2011) approaches were implemented with array-base methods, allowing quantifying methylation levels throughout the genome. Although DNA microarray approaches are relatively affordable and enable us to compare multiple samples simultaneously, they rely on predesigned probes that limit and bias the genomic areas that are being covered. Furthermore, only sequencingbased approaches allow studying inherent variations at single-base resolution. In recent years, advancement in next-generation sequencing technologies enabled the application of immunoprecipitation-based (Maunakea et al. 2010) and bisulfite sequencing-based (Meissner et al. 2005) methodologies to study DNA methylation sequences in segments of the genome. Finally, treatment of DNA with bisulfite facilitated full methylome with single-base resolution. In 2008, the complete map of Arabidopsis thaliana methylome was published (Cokus et al. 2008), followed by the first human single-base-resolution methylome obtained from embryonic stem cells and fibroblasts (Lister et al. 2009). In a combined effort of several laboratories in the field, recent studies established full singlebase methylomes of multiple human tissues and cell types (Smith et al. 2014; Roadmap Epigenomics Consortium et al. 2015; Schultz et al. 2015). The recent expansion of high-quality data allows novel insights into the interplay between DNA methylation and other epigenetic mechanisms and into the regulation and maintenance of cell identity during development and disease (Rivera and Ren 2013; Romanoski et al. 2015).

\section{LIMITATIONS OF CURRENT METHODOLOGIES}

Methods that are currently used to study DNA methylation share two fundamental experimental constraints. (i) Most methods require the examination of multiple cells, thus precluding assessment of methylation heterogeneity at the single-cell level. Notably, single-cell genome-wide sequencing was recently reported (Guo et al. 2013; Smallwood et al. 2014; Farlik et al. 2015), albeit with limited coverage. Nevertheless, similar to recent advancement in single-cell RNA sequencing (Deng et al. 2014; Jaitin et al. 2014; Klein et al. 2015), future improvement of current methodologies will most likely allow us to obtain high-quality single-cell DNA methylation maps. (ii) More importantly, all approaches require the extraction of DNA and thus provide only a static "snapshot" view of methylation at a given cell state. This is a serious limitation as it precludes monitoring dynamic changes of DNA methylation. Furthermore, cur- 
rent methods do not allow the prospective isolation of cells with a given change in methylation, thus impeding mechanistic studies of methylation and gene regulation during cell fate transitions.

\section{ESTABLISHING A TRACEABLE READOUT OF ENDOGENOUS DNA METHYLATION STATE}

We have recently established a reporter system that allows monitoring endogenous changes in DNA methylation at single-cell resolution (Stelzer et al. 2015). To obtain a signal that correlates with the methylation state of a given region of interest, we sought to translate endogenous methylation levels into a traceable transcriptional readout. The design of the reporter was based on using the activity of a gene promoter to reflect the methylation state of the surrounding sequences. We reasoned that the promoter should be activated or repressed by the DNA methylation state of adjacent sequences without being a target of trans-acting factors that affect methylation. The most widespread classes of promoters in the mammalian genome are associated with housekeeping genes or developmentally regulated genes. Housekeeping genes are expressed in all tissues and consist of highdensity $\mathrm{CpG}$ regions in their promoters (termed $\mathrm{CpG}$ is- lands, CGIs) that are protected from de novo methylation (Fig. 1A; Jones 2012). Most of the developmentally regulated genes exhibit low-density CGIs in their promoter region that can be repressed by de novo methylation or activated by demethylation in a tissue-dependent manner (Cedar and Bergman 2012; Jones 2012). Therefore, both types of promoters cannot be used as methylation reporters for surrounding sequences (Fig. 1B).

Parental imprinting is a form of epigenetic regulation that results in parent-of-origin monoallelic gene expression (Reik et al. 2001). The imprinted marks are established by differential DNA methylation in the germ cells, also known as germline differentially methylated regions (gDMRs). During fertilization, gDMRs are protected from demethylation, allowing for the imprints to be faithfully maintained throughout the development of the embryo. Subsequently, at the blastocyst stage a new methylation landscape is established by the de novo DNA methyltransferases (Dnmt3a and Dnmt3b) during subsequent cellular differentiation. At this stage transcriptionally associated secondary DMRs (or somatic DMRs) are established at the promoters of many imprinted genes (Morgan et al. 2005; Ferguson-Smith 2011). These somatic DMRs depend on the regional gDMRs, which serve as cis elements mediating the allele-specific marks.
Cell type A

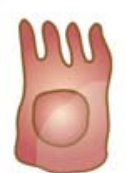

A
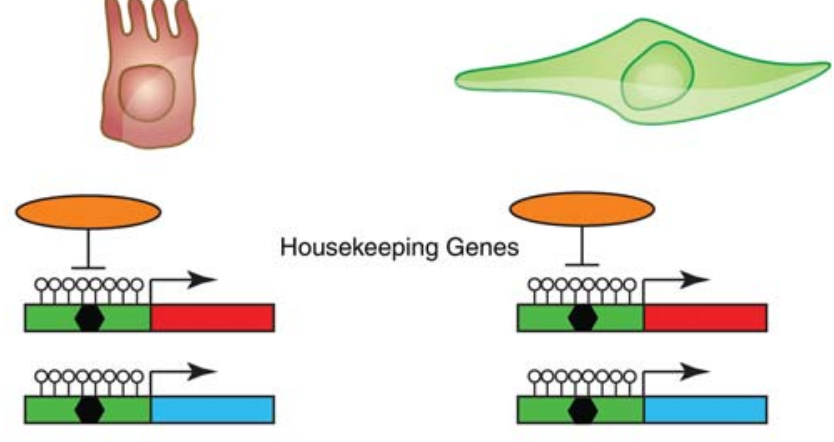

B

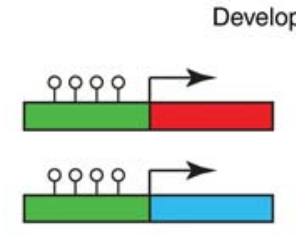

C

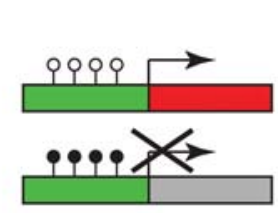

Imprinted Genes

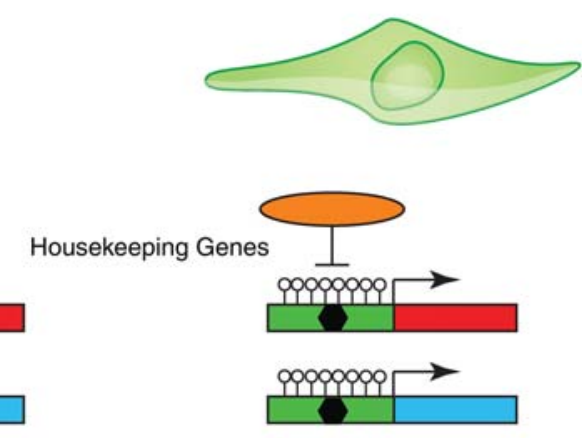

Cell type B

evelopmentally regulated Genes
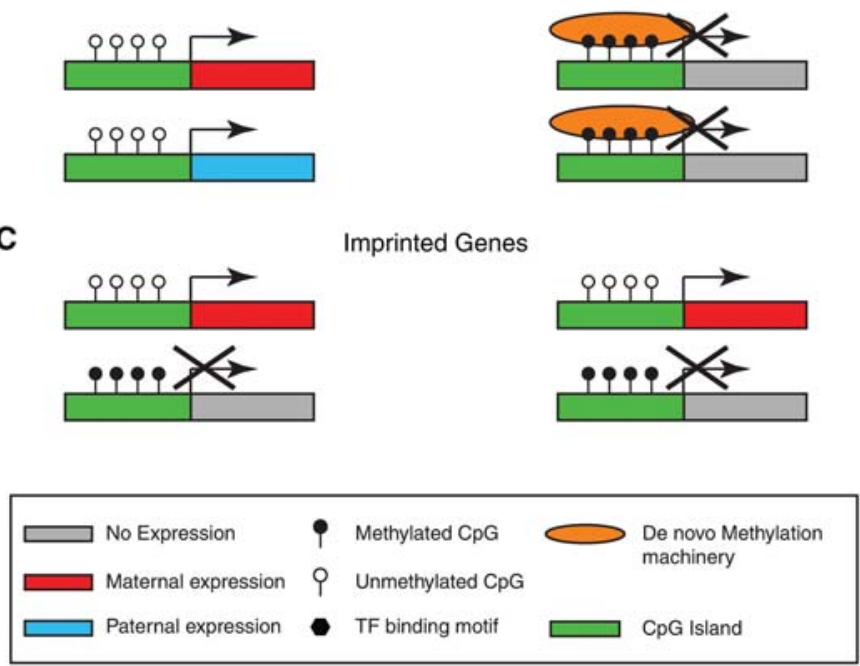

Figure 1. Regulatory principles of different types of mammalian promoters in adult tissues. (A) Housekeeping genes usually comprise high-density $\mathrm{CpG}$ islands (CGIs) in their promoter region, which include a transcription factor (TF) binding motif that protects from de novo methylation. (B) Developmentally regulated genes show low-density CGI in their promoter region, which is regulated by the methylation machinery in a tissue-dependent manner. $(C)$ Imprinted gene promoters are controlled by differentially methylated regions (DMRs) in their promoter. Note that in most cases the methylated allele represses the expression of the downstream gene, resulting in monoallelic expression solely from the unmethylated allele. Following their establishment in the germline or following fertilization, the promoter-associated DMRs are resistant to the global demethylation and de novo methylation imposed on the genome during early development. 
A

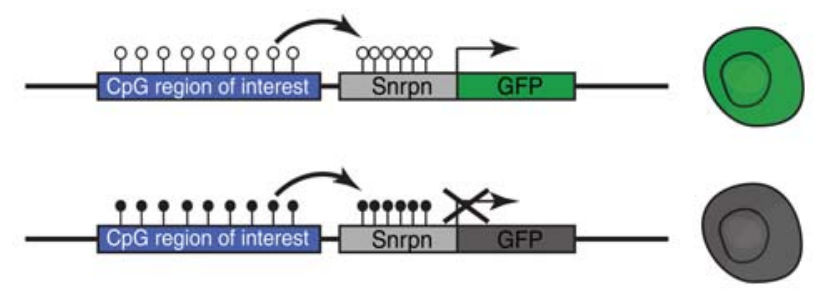

B $\quad \underline{\text { Dazl }}$

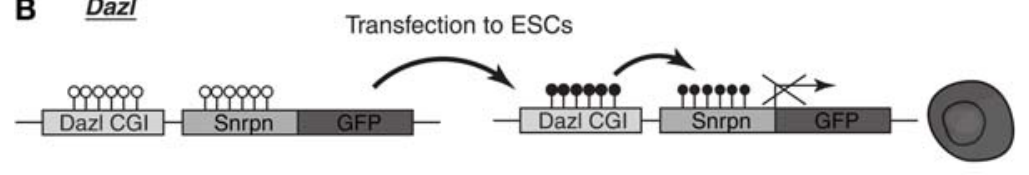

C Gapdh

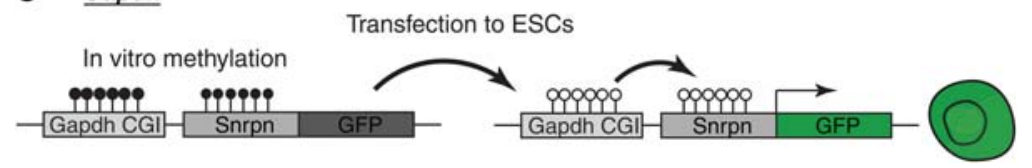

Figure 2. Characteristics of the methylation reporter. $(A)$ The principles of activation and repression of the Snrpn promoter by spreading of methylation and demethylation into the promoter region (upper panel), resulting in differential expression of green fluorescent protein (GFP). (B) Stable integration of Dazl reporter construct into ESCs results in silencing of Snrpn transcriptional activity by means of spreading of de novo methylation from the Dazl CGI into the promoter region. (C) Stable integration of the in vitro methylated Gapdh reporter construct into ESCs results in reactivation of Snrpn transcriptional activity by demethylation of both the Gapdh CGI and the downstream Snrpn promoter regions.

Unlike housekeeping or developmentally regulated genes, imprinted genes that contain somatic DMRs in their promoter region can serve as natural methylation reporters (Fig. 1C) as they fulfill the following criteria: (i) the promoter-associated DMR regulates the parent-oforigin expression of its downstream gene; and (ii) following their establishment, somatic DMRs are maintained throughout development and are not regulated by transacting signals from the DNA methylation machinery (Fig. 1C). Most importantly, expression of the imprinted gene strictly depends on the methylation state of the adjacent sequences (DMR) and is not susceptible to transacting factors (Fig. 2A). To generate a DNA methylation reporter, we used the small nuclear ribonucleoprotein polypeptide N (Snrpn) gene promoter region which resides in the Prader-Willi/Angelman region (Edwards and Ferguson-Smith 2007). Snrpn was chosen because, unlike other imprinted genes that contain DMR in their promoter region (e.g., Meg3, Gnas, Kcnq1 ot1, Peg10), it is expressed in most, if not all, tissues and therefore can serve as a general reporter.

The basic assumption for construction of the reporter was the concept that methylation can spread from adjacent sequences into the promoter and regulate its expression. The notion of spreading of DNA methylation from cis-acting foci is based on early studies identifying specific sequence elements that protect CGIs from de novo methylation (Brandeis et al. 1994; Macleod et al. 1994). Elimination of transcription factor (TF) binding motifs results in de novo methylation of the CGIs. However, many CpGs outside of the core sequence motifs are affected and become methylated, suggesting that methylation can be propagated and affect adjacent sequences, (Fig. 2A; Turker 2002; Irizarry et al. 2009). To test this hypothesis, we designed an experimental system in which the promoter-associated CGIs of Dazl and Gapdh genes were cloned upstream of the Snrpn promoter. Dazl represents a developmentally regulated gene that shows hypermethylation in ESCs. Therefore, upon introduction to ESCs the Dazl CGI acquired de novo methylation, which spread downstream into the Snrpn promoter region, resulting in its transcriptional silencing (Fig 2B; Stelzer et al. 2015). Gapdh represents a housekeeping gene that shows stably hypomethylated CGI in its promoter region. We therefore introduced an in vitro methylated Gapdh reporter construct into ESCs resulting in demethylation of the Gapdh CGI and the Snrpn promoter region, (Fig. 2C; Stelzer et al. 2015).

\section{REPORTING ON THE METHYLATION STATE OF GENOMIC SEQUENCES}

We showed that the Snrpn promoter construct senses DNA methylation and demethylation of surrounding sequences and thus can faithfully report on the methylation state of endogenous sequences as well as on methylation dynamics during cell-state changes (Stelzer et al. 2015). Using the Snrpn reporter we visualized the state of methylation and the dynamic changes associated with three types of endogenous sequences.

\section{Endogenous Promoters}

We used CRISPR/Cas gene editing to integrate the Snrpn promoter downstream from CGIs associated with both housekeeping (Gapdh) and tissue-specific (Dazl) gene promoters. Similar to the transgene experiments 
(Fig. 2B,C), targeting of endogenous promoters resulted in differential methylation and activity of the Snrpn reporter (Fig 2A). These results showed that the Snrpn reporter effectively reflects local methylation patterns associated with gene promoters without affecting the endogenous epigenetic state (Stelzer et al. 2015).

\section{Enhancers}

In addition to CGIs located at gene promoters, we also showed that it is possible to use the Snrpn promoter to report on the methylation state of noncoding superenhancer (SE) regions (Hnisz et al. 2013; Whyte et al. 2013; Stelzer et al. 2015). Unlike gene promoters, SEs are large regions comprising low-density CpGs that are implicated to regulate cell type-specific transcription. In this case, integrating the Snrpn promoter within the boundaries of a large regulatory region may represent a different mechanism by which the methylation reporter can be used. Thus, the Snrpn promoter may serve as a regional sensor for methylation changes, as the entire region is subjected to epigenomic changes in a tissuedependent manner.

\section{Imprinted DMRs}

As the majority of tissue-specific methylation changes occur in noncoding distal regulatory regions, a valuable application of the Snrpn promoter would be reporting on discrete genomic elements such as DMRs. To test this, we performed allele-specific targeting of the methylation reporter in proximity to an imprinted gDMR region, resulting in correct parent-of-origin differential expression of the Snrpn promoter (Y Stelzer, et al., unpubl.). Allele-specific methylation reporter of an imprinted DMR may allow monitoring of the erasure and establishment of the parental marks in the germline, as well as maintenance in adult tissues. Furthermore, successful targeting of a distinct imprinted DMR suggests that the Snrpn promoter holds the promise to faithfully report on methylation changes associated with discrete tissue-specific regulatory elements in the context of development and disease.

\section{APPLICATIONS OF THE DNA METHYLATION REPORTER}

Establishing a locus-specific readout of endogenous methylation states holds great promise for mechanistic studies with potential broad implications for the field. An attractive feature of the methylation reporter is that it allows monitoring DNA methylation dynamics during cell fate changes both in vitro and in vivo (Stelzer et al. 2015). This enables tracing methylation changes during development and disease (Fig. 3A). For example, it will be of interest to use the methylation reporter to study kinetics of demethylation and de novo methylation following fertilization, germ cell development, and embryonic differentiation, which constitute cornerstones of developmental biology in which DNA methylation is most dynamic (Lee et al. 2014). Furthermore, using DNA methylation reporter together with conventional gene expression reporters will allow studying the elusive interplay between epigenetics and gene regulation. Alternatively, replacing the fluorescent protein with Cre recombinase will allow for the permanent marking of cells following locus-specific methylation changes, thus establishing epigenetic lineage-tracing maps during development or disease (Fig. 3B).

Recent advances in high-throughput single-cell RNA sequencing technology show overwhelming cell-to-cell heterogeneity in different cell types and tissues (Deng et al. 2014; Jaitin et al. 2014; Klein et al. 2015). However, little is known about the epigenetic heterogeneity, which may introduce additional complexity to our understanding of gene regulation and cell identity. Together with recent promising advances in single-cell methylation sequencing (Guo et al. 2013; Smallwood et al. 2014), the DNA methylation reporter will allow us to further evaluate the magnitude of cell-to-cell heterogeneity (Fig. 3C). Furthermore, the methylation reporter enables us to measure dynamics of heterogeneous cell populations over time, with single-cell resolution. This facilitates a unique experimental system that allows measurement of the effects of external cues, such as culture conditions or perturbations, on the overall levels of heterogeneity (Fig. 3C).

Another potential application of obtaining locus-specific methylation readout involves unbiased screens to identify putative regulators of methylation and demethylation at different genomic contexts (Fig. 3D). In addition, as alterations in DNA methylation are known to play a role in cancer and disease (Robertson 2005), an attractive aspect of such screens would be to search for small molecules or drugs that reverse the epigenetic phenotype (Fig. 3D). Finally, perturbation in parental imprinting is known to play a role in disease (Stelzer et al. 2011, 2014) and transformation (Stelzer et al. 2013). However, using current methodologies to identify rare events of loss of imprinting in heterogeneous cell populations is highly challenging. Using the Snrpn promoter to report on the methylation state of imprinted DMRs allows us to detect and isolate cells that show loss of imprinting during development and disease (Fig. 3E).

\section{LIMITATIONS AND CHALLENGES}

As with any fluorescent protein-based reporter system, the accuracy of tracing real-time changes in gene expression depends on the half-life of the respective protein. Therefore, facilitating the reporter to study fast kinetics of de novo DNA methylation would require the use of a destabilized fluorescent protein. Alternatively, an intrinsic limitation of the reporter is that endogenous demethylation changes are translated to a readout through transcription of the Snrpn promoter, therefore representing merely a close estimation of the real-time demethylation kinetics.

Because the design of the reporter is based on translating endogenous methylation levels into transcription 
A Dynamics of DNA methylation

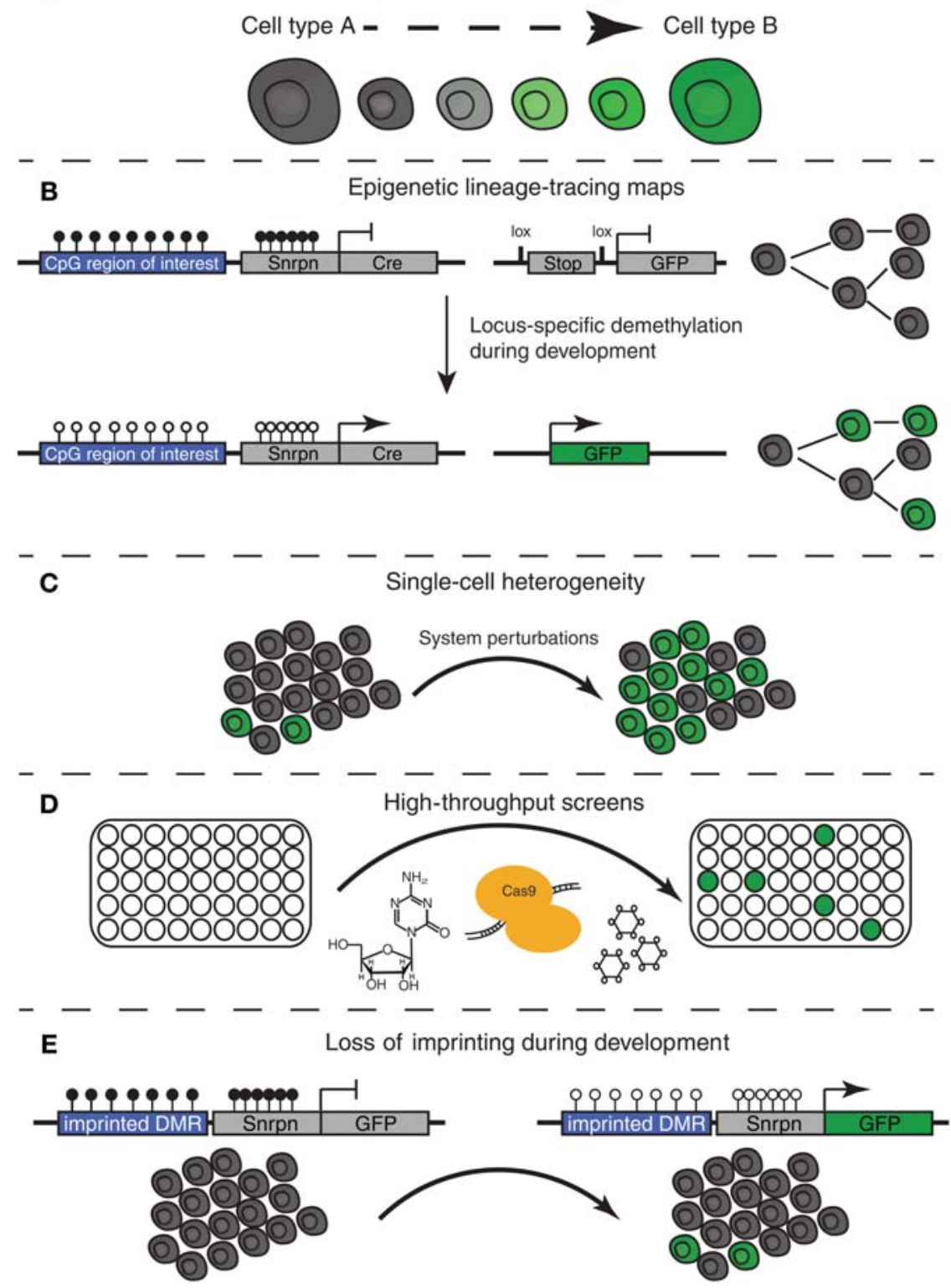

Figure 3. Potential applications of methylation reporter. (A) Monitoring dynamics of methylation during cell fate transitions with single-cell resolution. $(B)$ Using Cre recombinase would allow the generation of locus-specific epigenetic lineage-tracing maps. $(C)$ The methylation reporter allows studying cell-to-cell heterogeneity in steady-state and during population dynamics. $(D)$ Having a traceable readout facilitates unbiased screens for locus-specific methylation regulators. Examples of commonly used screening platforms are shown: small molecules, Crispr/Cas9, and viruses-mediated screens. $(E)$ The methylation reporter allows tracing rare events of loss of imprinting in heterogeneous cell populations during development and disease.

readout, blocking the transcription of the Snrpn promoter by means other than DNA methylation will result in false readout. Therefore, it is possible that other locus-specific epigenetic modifications such as chromatin or insulators will uncouple the transcription of the Snrpn promoter from its methylation state.

\section{CONCLUSIONS}

During the past 50 years, cytosine methylation has been extensively studied in the context of mammalian development and shown to play diverse roles in regulating fundamental developmental processes such as parental imprinting, $\mathrm{X}$ inactivation, repetitive elements, and tissue-specific transcription (Jones 2012). DNA methylation has been associated with transcriptional silencing as first shown for retroviral genes (Harbers et al. 1981; Stuhlmann et al. 1981). However, except for regulation of parental imprinting, transposable elements and some tissue-specific genes, the correlation between DNA methylation and gene silencing is not well established (Schübeler 2015). The recent discovery of the 10-11 translocation (TET) family of proteins that oxidize $5 \mathrm{mC}$, and thymine DNA glycosylase (TDG)-mediated base ex- 
cision repair (Kohli and Zhang 2013), support a more complex role for DNA methylation in regulating gene expression and tissue-specific programs.

Epigenomic maps obtained from multiple tissues showed unexpected methylation dynamics at distal noncoding regulatory regions (Schübeler 2015). These cell type-specific DMRs establish an attractive list of candidate regions to generate methylation reporter cell lines (Stelzer et al. 2015). Combining this methodology with genome-wide methods and gene-expression reporters facilitates the framework to experimentally address open questions in the field, such as the interplay between DNA methylation and cell type-specific programs in development and disease.

Finally, as the design of the reporter is based on a minimal promoter region of Snrpn, which is highly conserved among placental mammals, it will be of interest to test the methylation reporter in other model organisms and human cells. Moreover, as cytosine methylation is also widespread in fish and plants, it will be of interest to establish loci-specific methylation reporters in these species. The same principles that were used to establish the reporter in mammals may apply for plants, whereas for fish, which lack parental imprinting, the transcription of the Snrpn minimal promoter needs to be tested.

\section{ACKNOWLEDGMENTS}

We would like to apologize to colleagues whose work we could not cite because of space or context limitations. Y.S. is supported by a Human Frontier Postdoctoral Fellowship and the laboratory DNA methylation-related work was supported by National Institutes of Health grant \# HD 045022. R.J. is cofounder of Fate Therapeutics and an adviser to Stemgent.

\section{REFERENCES}

Adouard V, Dante R, Niveleau A, Delain E, Revet B, Ehrlich M. 1985. The accessibility of 5-methylcytosine to specific antibodies in double-stranded DNA of Xanthomonas phage XP12. Eur J Biochem 152: 115-121.

Annan RS, Kresbach GM, Giese RW, Vouros P. 1989. Trace detection of modified DNA bases via moving-belt liquid chromatography-mass spectrometry using electrophoric derivatization and negative chemical ionization. J Chromatogr 465: 285-296.

Baylin SB, Jones PA. 2011. A decade of exploring the cancer epigenome-Biological and translational implications. Nat Rev Cancer 11: 726-734.

Bestor TH, Hellewell SB, Ingram VM. 1984. Differentiation of two mouse cell lines is associated with hypomethylation of their genomes. Mol Cell Biol 4: 1800-1806.

Bird AP, Southern EM. 1978. Use of restriction enzymes to study eukaryotic DNA methylation: I. The methylation pattern in ribosomal DNA from Xenopus laevis. J Mol Biol 118: 27-47.

Brandeis M, Frank D, Keshet I, Siegfried Z, Mendelsohn M, Nemes A, Temper V, Razin A, Cedar H. 1994. Sp1 elements protect a $\mathrm{CpG}$ island from de novo methylation. Nature 371: 435-438.

Cedar H, Bergman Y. 2012. Programming of DNA methylation patterns. Ann Rev Biochem 81: 97-117.
Cedar H, Solage A, Glaser G, Razin A. 1979. Direct detection of methylated cytosine in DNA by use of the restriction enzyme MspI. Nucleic Acids Res 6: 2125-2132.

Chen RZ, Pettersson U, Beard C, Jackson-Grusby L, Jaenisch R. 1998. DNA hypomethylation leads to elevated mutation rates. Nature 395: 89-93.

Clark SJ, Harrison J, Paul CL, Frommer M. 1994. High sensitivity mapping of methylated cytosines. Nucleic Acids Res 22: 2990-2997.

Cokus SJ, Feng S, Zhang X, Chen Z, Merriman B, Haudenschild CD, Pradhan S, Nelson SF, Pellegrini M, Jacobsen SE. 2008. Shotgun bisulphite sequencing of the Arabidopsis genome reveals DNA methylation patterning. Nature 452: 215-219.

Deng Q, Ramsköld D, Reinius B, Sandberg R. 2014. Single-cell RNA-seq reveals dynamic, random monoallelic gene expression in mammalian cells. Science 343: 193-196.

Eden A, Gaudet F, Waghmare A, Jaenisch R. 2003. Chromosomal instability and tumors promoted by DNA hypomethylation. Science 300: 455.

Edwards CA, Ferguson-Smith AC. 2007. Mechanisms regulating imprinted genes in clusters. Curr Opin Cell Biol 19: 281289.

Farlik M, Sheffield NC, Nuzzo A, Datlinger P, Schönegger A, Klughammer J, Bock C. 2015. Single-cell DNA methylome sequencing and bioinformatic inference of epigenomic cellstate dynamics. Cell Rep 10: 1386-1397.

Feinberg AP, Vogelstein B. 1983. Hypomethylation distinguishes genes of some human cancers from their normal counterparts. Nature 301: 89-92.

Ferguson-Smith AC. 2011. Genomic imprinting: The emergence of an epigenetic paradigm. Nat Rev Genet 12: 565575.

Frommer M, McDonald LE, Millar DS, Collis CM, Watt F, Grigg GW, Molloy PL, Paul CL. 1992. A genomic sequencing protocol that yields a positive display of 5-methylcytosine residues in individual DNA strands. Proc Natl Acad Sci 89: $1827-1831$.

Gama-Sosa MA, Midgett RM, Slagel VA, Githens S, Kuo KC, Gehrke CW, Ehrlich M. 1983. Tissue-specific differences in DNA methylation in various mammals. Biochim Biophys Acta 740: 212-219.

Gaudet F, Hodgson JG, Eden A, Jackson-Grusby L, Dausman J, Gray JW, Leonhardt H, Jaenisch R. 2003. Induction of tumors in mice by genomic hypomethylation. Science 300: 489-492.

Gitan RS, Shi H, Chen CM, Yan PS, Huang TH. 2002. Methylation-specific oligonucleotide microarray: A new potential for high-throughput methylation analysis. Genome Res 12: $158-164$.

Guo H, Zhu P, Wu X, Li X, Wen L, Tang F. 2013. Single-cell methylome landscapes of mouse embryonic stem cells and early embryos analyzed using reduced representation bisulfite sequencing. Genome Res 23: 2126-2135.

Harbers K, Schnieke A, Stuhlmann H, Jähner D, Jaenisch R. 1981. DNA methylation and gene expression: Endogenous retroviral genome becomes infectious after molecular cloning. Proc Natl Acad Sci 78: 7609-7613.

Harrison A, Parle-McDermott A. 2011. DNA methylation: A timeline of methods and applications. Front Genet 2: 74.

Hayatsu H, Wataya Y, Kai K, Iida S. 1970. Reaction of sodium bisulfite with uracil, cytosine, and their derivatives. Biochemistry 9: $2858-2865$.

Heard E, Martienssen RA. 2014. Transgenerational epigenetic inheritance: Myths and mechanisms. Cell 157: 95-109.

Herman JG, Graff JR, Myöhänen S, Nelkin BD, Baylin SB. 1996. Methylation-specific PCR: A novel PCR assay for methylation status of $\mathrm{CpG}$ islands. Proc Natl Acad Sci 93: 9821-9826.

Hnisz D, Abraham BJ, Lee TI, Lau A, Saint-André V, Sigova AA, Hoke HA, Young RA. 2013. Super-enhancers in the control of cell identity and disease. Cell 155: 934-947.

Holliday R, Pugh JE. 1975. DNA modification mechanisms and gene activity during development. Science 187: 226-232. 
Hon GC, Rajagopal N, Shen Y, McCleary DF, Yue F, Dang MD, Ren B. 2013. Epigenetic memory at embryonic enhancers identified in DNA methylation maps from adult mouse tissues. Nat Genet 45: 1198-1206.

Irizarry RA, Ladd-Acosta C, Wen B, Wu Z, Montano C, Onyango P, Cui H, Gabo K, Rongione M, Webster M, et al. 2009. The human colon cancer methylome shows similar hypo- and hypermethylation at conserved tissue-specific CpG island shores. Nat Genet 41: 178-186.

Jaitin DA, Kenigsberg E, Keren-Shaul H, Elefant N, Paul F, Zaretsky I, Mildner A, Cohen N, Jung S, Tanay A, et al. 2014. Massively parallel single-cell RNA-seq for markerfree decomposition of tissues into cell types. Science 343: 776-779.

Jones PA. 2012. Functions of DNA methylation: Islands, start sites, gene bodies and beyond. Nat Rev Genet 13: 484-492.

Keshet I, Schlesinger Y, Farkash S, Rand E, Hecht M, Segal E, Pikarski E, Young RA, Niveleau A, Cedar H, et al. 2006. Evidence for an instructive mechanism of de novo methylation in cancer cells. Nat Genet 38: 149-153.

Klein AM, Mazutis L, Akartuna I, Tallapragada N, Veres A, Li V, Peshkin L, Weitz DA, Kirschner MW. 2015. Droplet barcoding for single-cell transcriptomics applied to embryonic stem cells. Cell 161: 1187-1201.

Kohli RM, Zhang Y. 2013. TET enzymes, TDG and the dynamics of DNA demethylation. Nature 502: 472-479.

Kuo KC, McCune RA, Gehrke CW, Midgett R, Ehrlich M. 1980. Quantitative reversed-phase high performance liquid chromatographic determination of major and modified deoxyribonucleosides in DNA. Nucleic Acids Res 8: 4763-4776.

Laird PW, Jackson-Grusby L, Fazeli A, Dickinson SL, Jung WE, Li E, Weinberg RA, Jaenisch R. 1995. Suppression of intestinal neoplasia by DNA hypomethylation. Cell 81: 197205.

Lander ES. 2011. Initial impact of the sequencing of the human genome. Nature 470: 187-197.

Lee HJ, Hore TA, Reik W. 2014. Reprogramming the methylome: Erasing memory and creating diversity. Cell Stem Cell 14: $710-719$.

Li E, Bestor TH, Jaenisch R. 1992. Targeted mutation of the DNA methyltransferase gene results in embryonic lethality. Cell 69: 915-926.

Li E, Beard C, Jaenisch R. 1993. Role for DNA methylation in genomic imprinting. Nature 366: 362-365.

Lister R, Pelizzola M, Dowen RH, Hawkins RD, Hon G, TontiFilippini J, Nery JR, Lee L, Ye Z, Ngo QM, et al. 2009. Human DNA methylomes at base resolution show widespread epigenomic differences. Nature 462: 315-322.

Macleod D, Charlton J, Mullins J, Bird AP. 1994. Sp1 sites in the mouse aprt gene promoter are required to prevent methylation of the CpG island. Genes Dev 8: 2282-2292.

Maunakea AK, Nagarajan RP, Bilenky M, Ballinger TJ, D'Souza C, Fouse SD, Johnson BE, Hong C, Nielsen C, Zhao Y, et al. 2010. Conserved role of intragenic DNA methylation in regulating alternative promoters. Nature 466: $253-$ 257.

Meissner A, Gnirke A, Bell GW, Ramsahoye B, Lander ES, Jaenisch R. 2005. Reduced representation bisulfite sequencing for comparative high-resolution DNA methylation analysis. Nucleic Acids Res 33: 5868-5877.

Monk M, Boubelik M, Lehnert S. 1987. Temporal and regional changes in DNA methylation in the embryonic, extraembryonic and germ cell lineages during mouse embryo development. Development 99: 371-382.

Morgan HD, Santos F, Green K, Dean W, Reik W. 2005. Epigenetic reprogramming in mammals. Hum Mol Genet 14(Spec No 1): R47-R58.

Oakeley EJ, Podestà A, Jost JP. 1997. Developmental changes in DNA methylation of the two tobacco pollen nuclei during maturation. Proc Natl Acad Sci 94: 11721-11725.
Okano M, Bell DW, Haber DA, Li E. 1999. DNA methyltransferases Dnmt3a and Dnmt3b are essential for de novo methylation and mammalian development. Cell 99: 247-257.

Panning B, Jaenisch R. 1996. DNA hypomethylation can activate Xist expression and silence X-linked genes. Genes Dev 10: $1991-2002$.

Reik W, Dean W, Walter J. 2001. Epigenetic reprogramming in mammalian development. Science 293: 1089-1093.

Riggs AD. 1975. X inactivation, differentiation, and DNA methylation. Cytogenet Cell Genet 14: 9-25.

Rivera CM, Ren B. 2013. Mapping human epigenomes. Cell 155: 39-55.

Roadmap Epigenomics Consortium, Kundaje A, Meuleman W, Ernst J, Bilenky M, Yen A, Heravi-Moussavi A, Kheradpour $\mathrm{P}$, Zhang Z, Wang J, et al. 2015. Integrative analysis of 111 reference human epigenomes. Nature 518: 317-330.

Robertson KD. 2005. DNA methylation and human disease. Nat Rev Genet 6: 597-610.

Romanoski CE, Glass CK, Stunnenberg HG, Wilson L, Almouzni G. 2015. Epigenomics: Roadmap for regulation. Nature 518: 314-316.

Sandoval J, Heyn H, Moran S, Serra-Musach J, Pujana MA, Bibikova M, Esteller M. 2011. Validation of a DNA methylation microarray for $450,000 \mathrm{CpG}$ sites in the human genome. Epigenetics 6: 692-702.

Schübeler D. 2015. Function and information content of DNA methylation. Nature 517: 321-326.

Schultz MD, He Y, Whitaker JW, Hariharan M, Mukamel EA, Leung D, Rajagopal N, Nery JR, Urich MA, Chen H, et al. 2015. Human body epigenome maps reveal noncanonical DNA methylation variation. Nature 523: 212-216.

Smallwood SA, Lee HJ, Angermueller C, Krueger F, Saadeh H, Peat J, Andrews SR, Stegle O, Reik W, Kelsey G. 2014. Single-cell genome-wide bisulfite sequencing for assessing epigenetic heterogeneity. Nat Methods 11: 817-820.

Smith ZD, Meissner A. 2013. DNA methylation: Roles in mammalian development. Nat Rev Genet 14: 204-220.

Smith ZD, Chan MM, Humm KC, Karnik R, Mekhoubad S, Regev A, Eggan K, Meissner A. 2014. DNA methylation dynamics of the human preimplantation embryo. Nature 511: $611-615$.

Southern E, Mir K, Shchepinov M. 1999. Molecular interactions on microarrays. Nat Genet 21: 5-9.

Stelzer Y, Yanuka O, Benvenisty N. 2011. Global analysis of parental imprinting in human parthenogenetic induced pluripotent stem cells. Nat Struct Mol Biol 18: 735-741.

Stelzer Y, Sagi I, Benvenisty N. 2013. Involvement of parental imprinting in the antisense regulation of onco-miR-372-373. Nat Commun 4: 2724.

Stelzer Y, Sagi I, Yanuka O, Eiges R, Benvenisty N. 2014. The noncoding RNA IPW regulates the imprinted DLK1-DIO3 locus in an induced pluripotent stem cell model of PraderWilli syndrome. Nat Genet 46: 551-557.

Stelzer Y, Shivalila C, Soldner F, Markoulaki S, Jaenisch R. 2015. Tracing dynamic changes of DNA methylation at single cell resolution. Cell 163: 218-229.

Stuhlmann H, Jähner D, Jaenisch R. 1981. Infectivity and methylation of retroviral genomes is correlated with expression in the animal. Cell 26: 221-232.

Turker MS. 2002. Gene silencing in mammalian cells and the spread of DNA methylation. Oncogene 21: 5388-5393.

Weber M, Davies JJ, Wittig D, Oakeley EJ, Haase M, Lam WL, Schübeler D. 2005. Chromosome-wide and promoter-specific analyses identify sites of differential DNA methylation in normal and transformed human cells. Nat Genet 37: 853862.

Whyte WA, Orlando DA, Hnisz D, Abraham BJ, Lin CY, Kagey MH, Rahl PB, Lee TI, Young RA. 2013. Master transcription factors and mediator establish super-enhancers at key cell identity genes. Cell 153: 307-319. 


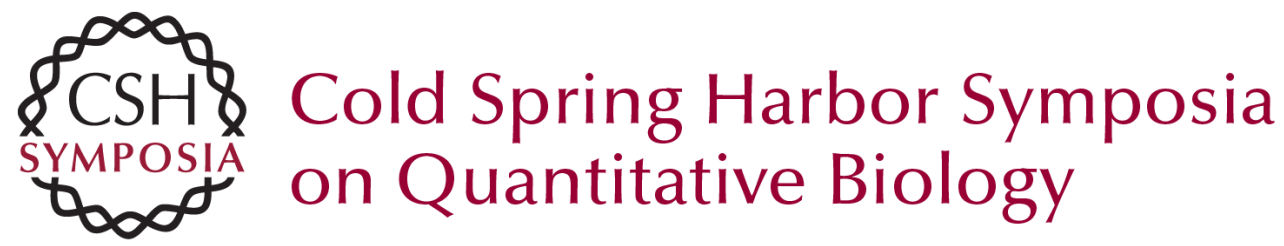

\section{Monitoring Dynamics of DNA Methylation at Single-Cell Resolution during Development and Disease}

Yonatan Stelzer and Rudolf Jaenisch

Cold Spring Harb Symp Quant Biol 2015 80: 199-206 originally published online October 2, 2015 Access the most recent version at doi:10.1101/sqb.2015.80.027334

References This article cites 72 articles, 16 of which can be accessed free at: http://symposium.cshlp.org/content/80/199.full.html\#ref-list-1

License

Email Alerting Receive free email alerts when new articles cite this article - sign up in Service the box at the top right corner of the article or click here. 